06

\title{
Термоокисление углеродного конденсата, полученного в потоке ВЧ углеродной и углеродно-никелевой плазмы
}

\author{
(ㄷ Г.Н. Чурилов, ${ }^{1,2}$ Н.С. Николаев, ${ }^{1,2}$ А.В. Черепахин, ${ }^{2}$ А.И. Дудник, ${ }^{1,2}$ Е.В. Томашевич, ${ }^{3}$ \\ М.В. Тренихин, ${ }^{4}$ Н.Г. Булина ${ }^{5}$ \\ ${ }^{1}$ Институт фризики им. Л.В. Киренского СО РАН, \\ 660036 Красноярск, Россия \\ ${ }^{2}$ Сибирский федеральный университет, \\ 660041 Красноярск, Россия \\ ${ }^{3}$ Институт химии и химической технологии СО РАН, \\ 660036 Красноярск, Россия \\ ${ }^{4}$ Институт проблем переработки углеводородов СО РАН, \\ 644040 Омск, Россия \\ ${ }^{5}$ Институт химии твердого тела и механохимии СО РАН, \\ 630128 Новосибирск, Россия \\ e-mail: churilov@iph.krasn.ru
}

(Поступило в Редакцию 24 июня 2017 г.)

Приведены сравнительные характеристи термического окисления углеродного конденсата (УК), полученного по методу высокочастотного - дугового испарения графитовых стержней и стержней, имеющих осевое отверстие, заполненное порошком никеля. Во втором случае кроме различных форм нанодисперсного углерода образуются наночастицы со структурой никелевое ядро-углеродная оболочка. Процессы термического окисления УК с содержанием никеля и без него протекали с существенными отличиями. Частицы никеля, имеющие углеродную оболочку, проявляли каталитические свойства по отношению к процессу окисления наноразмерных углеродных структур. Наблюдается существенное отличие температуры окончания процесса окисления различных наноразмерных частиц углерода и частиц никеля с углеродной оболочкой.

Задача настоящей работы - исследование влияния нанодисперсных частиц никеля на динамику окисления углеродного конденсата в результате нагрева в потоке аргонокислородной смены.

DOI: 10.21883/JTF.2018.02.45412.2406

\section{Введение}

Хорошо известно, что для ускорения процессов окисления различных продуктов на основе углерода в качестве катализаторов применяются металлы. Высокой каталитической активностью обладают 3-d металлы и металлы платиновой группы [1]. Металлы используются как в чистом, так и в нанесенном на углерод виде [2]. В процессе плазменного синтеза различных наноразмерных структур на основе углерода при введении металлов, кроме фуллеренов, нанотруб, графенов и аморфного углерода еще образуются и частицы со структурой металлическое ядро-углеродная оболочка [3].

\section{Экспериментальная часть}

Нами был проведен синтез углеродного конденсата (УК) в установке с ВЧ дуговыми разрядами в атмосфере гелия при его нормальном давлении [4]. В первом случае распылялись отожженные графитовые стержни марки ОСЧ диаметром $6 \mathrm{~mm}$. Во втором случае распыляемые стержни имели осевое отверстие, заполненное никелем. Никель составлял 19\% относительно общего веса распыляемой массы. Соответственно были получены образцы УК1 и УК2. Рентгенофазовый анализ показал, что в составе образца УК1 имеются фазы фуллеренов, графита и аморфного углерода, а в составе образца УК2, кроме вышеперечисленных содержится еще и фаза металлического никеля (рис. 1).

Во время распыления графитовых стержней с наполнением из никелевого порошка образуется никелево-

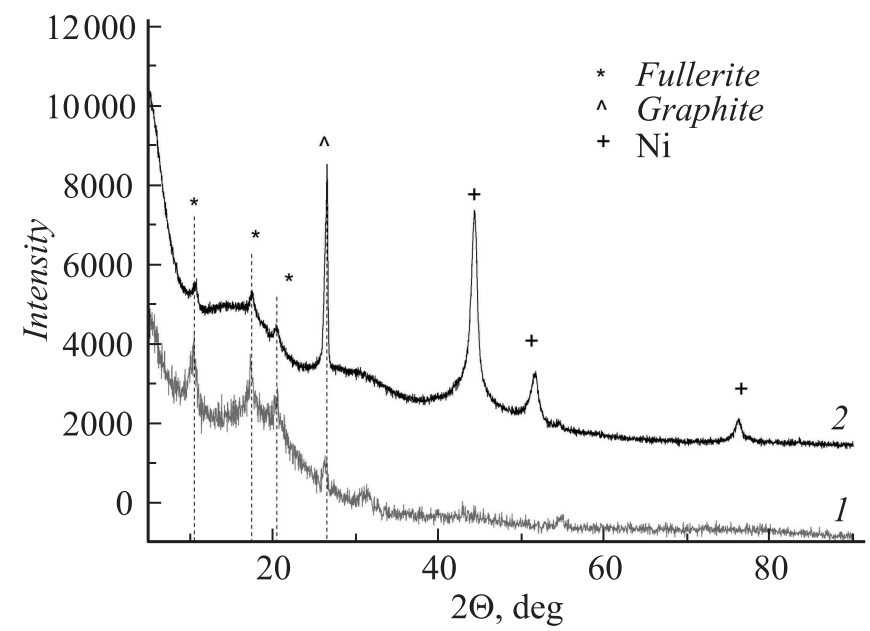

Рис. 1. Рентгенограммы образцов УК, синтезированного путем распыления графита ВЧ дуговым разрядом: 1 - УК1, 2 - УК2. Рентгенограммы были получены на порошковом дифрактометре Bruker, D8 Advance. 


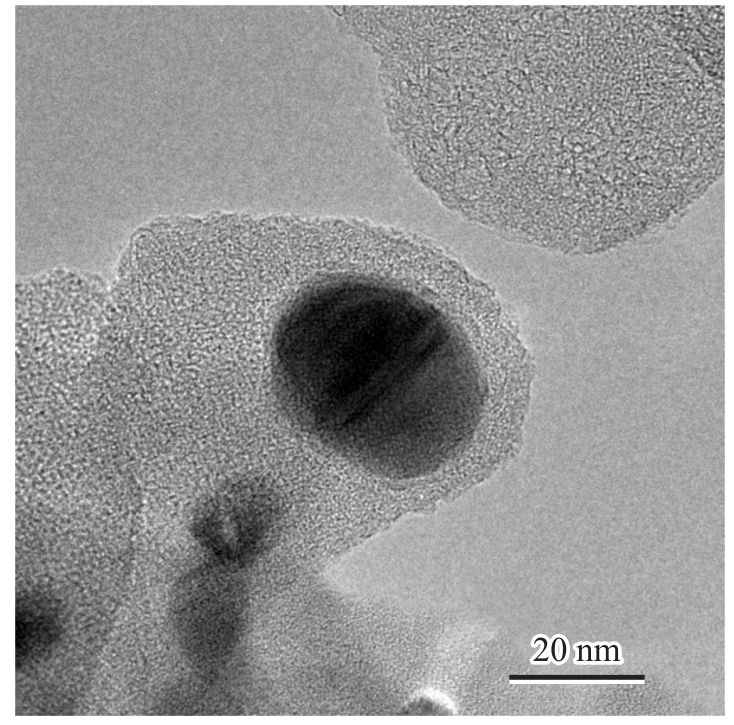

Рис. 2. Изображение образца УК2, полученное методом ПЭМ на приборе JEOL JEM-2100, ускоряющее напряжение 200 kV.

углеродная плазма. Покидая высокотемпературную область разряда, плазма остывает, переходя в состояние гомогенной смеси перегретых паров никеля и графита. Никель практически не растворяется в углероде, поэтому при конденсации паров никеля и углерода углерод выступает на поверхность жидких частиц никеля. Так как никель не существует в состоянии карбида $\left(\mathrm{Ni}_{3} \mathrm{C}\right)$ ниже $700^{\circ} \mathrm{C}$, то в процессе остывания формируются частицы со структурой никелевое ядро-углеродная оболочка $[4,5]$.

Из рис. 2 видно, что более контрастные области частицы никеля с хорошо выраженным слоем, распределены непосредственно в матрице из аморфного углерода. Оболочка никелевых частиц не отличается по контрастности от матрицы, но имеет заметную слоистую структуру.

\section{Результаты и обсуждения}

Исследование процесса окисления образцов УК1 и УК2 проводилось методами дифференциального термического анализа (ДТА) и термогравиметрического анализа (ТГА) с использованием системы синхронного термического анализа NETZSCH STA 449 C, Jupiter. Скорость нагрева образцов $10^{\circ} \mathrm{C} / \mathrm{min}$, осуществлялась в потоке смеси газов $\mathrm{Ar} / \mathrm{O}_{2}(80 \% / 20 \%)$.

Результат термогравиметрического анализа УК1 показан на рис. 3, a. В температурном интервале от 250 до $690^{\circ} \mathrm{C}$ протекает экзотермическая реакция. График температурной зависимости выделения теплоты имеет неровную форму с множеством пиков. Процесс сопровождается значительными потерями массы образца (около 90\%). Наиболее интенсивные потери происходят в температурном интервале от 390 до $620^{\circ} \mathrm{C}$. Этот процесс соответствует горению аморфного углерода и фуллеренов, а так же других наноструктурированных форм углерода [6].

УК, полученный дуговым распылением в атмосфере гелия, имеет растворимую часть, представляющую собой смесь фуллеренов [6,7].

ТГА растворимой части образца УК1 представлен на рис. $3, b$. Как видно из графика, в температурном интервале от 390 до $600^{\circ} \mathrm{C}$ наблюдается реакция, имеющая экзотермический эффект. Образец теряет 96\% массы в диапазоне температур от 450 до $580^{\circ} \mathrm{C}$. График температурной зависимости выделения теплоты имеет один
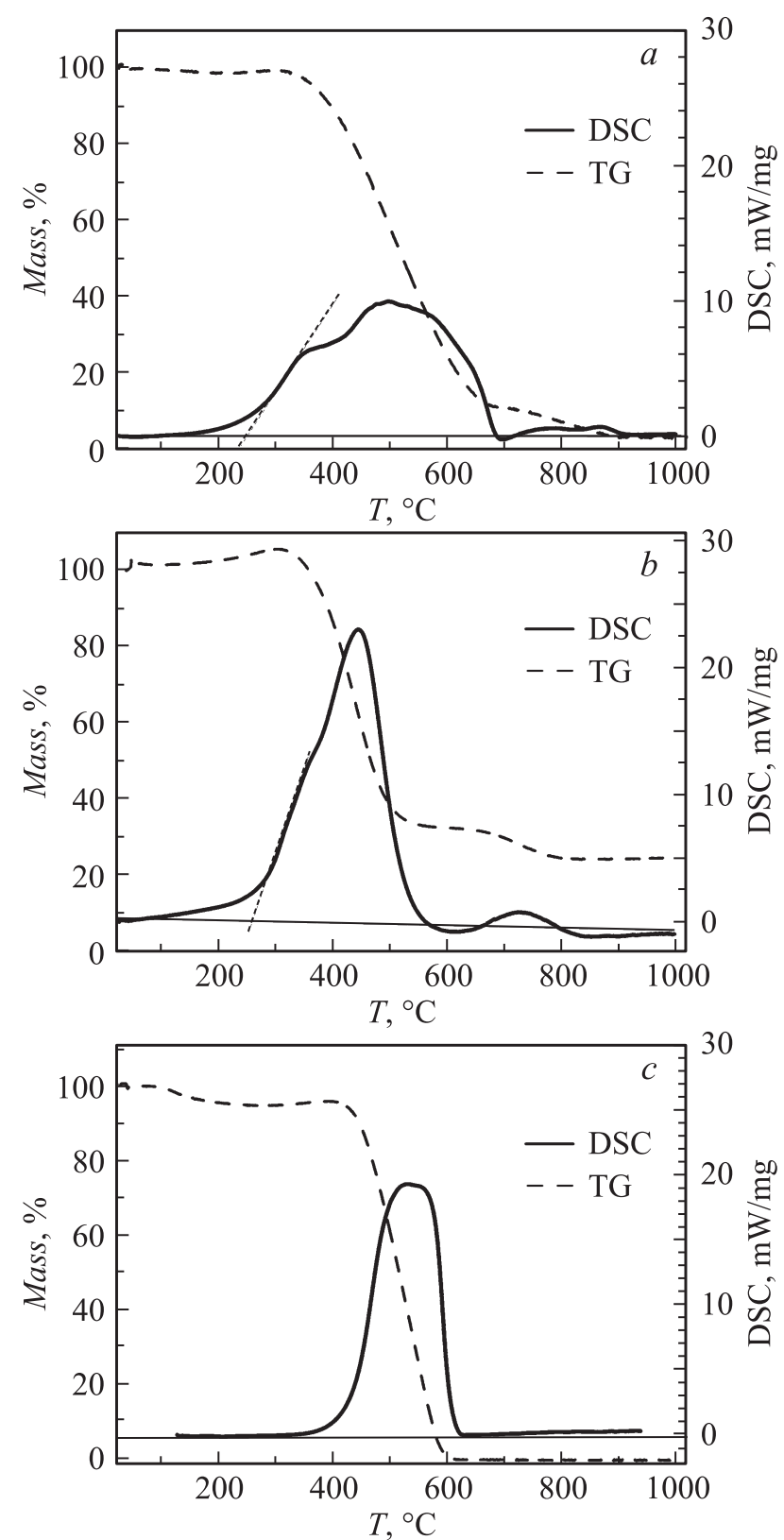

Рис. 3. Зависимость теплового потока от температуры нагрева в потоке газовой смеси аргона и кислорода: $a$ - для образца УК1, $b-$ для растворимой части образца УК1, $c-$ для образца УК2. 
четковыраженный уширенный пик. Уширение этого пика происходит вследствие различных температур реакции с кислородом для различных форм фуллеренов $[8,9]$.

Отметим, что энтальпия горения образцов УК1 и его растворимой части равны 17.4 и $19.3 \mathrm{~kJ} / \mathrm{g}$ соответственно. Это говорит о том, что реакция термоокисления фуллеренов вносит существенный вклад в выделение тепла в процесс окисления углеродного конденсата с содержанием фуллеренов.

Результат ТГА анализа образца УК2 показан на рис. 3,c. Характер изменений в УК2 сходен с УК1. Однако стоит отметить, что экзотермический пик в УК2 стал более компактным и имеет менее размытые пики. Реакция с выделением тепла наблюдается в температурном интервале от 280 до $536^{\circ} \mathrm{C}$. С потерей веса $62 \%$ наиболее интенсивно процесс происходит в интервале от 390 до $507^{\circ} \mathrm{C}$. Энтальпия окисления образца УК2 равна $14.9 \mathrm{~kJ} / \mathrm{g}$, что несколько ниже чем УК1. Связано это с тем, что по сравнению с образцом УК1 массовая доля фуллереновой смеси в образце УК2 ниже из-за присутствия никеля.

Кроме того, в образцах УК1 и УК2 в температурных интервалах от 700 до $920^{\circ} \mathrm{C}$ и от 620 до $850^{\circ} \mathrm{C}$ соответственно присутствует еще один экзотермический эффект, также сопровождающийся потерями веса. Потери веса составили $8 \%$ в УК1 и $5 \%$ в УК2.

Известно, что высокодисперсный графит реагирует с кислородом при температуре около $700^{\circ} \mathrm{C}$, а наноструктурированные продукты на основе углерода выгорают при температурах от 200 до $600^{\circ} \mathrm{C}$ [8,9]. Учитывая это, и связав данные рентгеноструктурного анализа (РСА) и ДСК образцов УК1 и УК2, можно сделать вывод о том, что эти образцы содержат графит. Это подтверждается и тем, что при окислении растворимой части УК1, не содержащей фазу графита, отсутствует экзотермический эффект в диапазоне от 650 до $1000^{\circ} \mathrm{C}$.

Образец УК2 был нагрет в дереватографе в тех же условиях. Нагрев был остановлен при температуре $550^{\circ} \mathrm{C}$, образец был изъят для исследований методами рентгеновской фотоэлектронной спектроскопии (РФЭС) и просвечивающей электронной микроскопии (ПЭМ).

Форма пиков никеля (рис. 4, $a$ ) практически не отличается от формы, характерной для соединения $\mathrm{NiO}$ [10-12], из-за большей дефектности структуры, а также образования незначительного количества поверхностного гидрооксида никеля. В спектрах кислорода по пику $\mathrm{O}^{2-}$, решетке $\mathrm{NiO}$ отвечает наиболее интенсивная линия с энергией связи $529.3 \mathrm{eV}$. Линия с энергией связи примерно $531 \mathrm{eV}$ соответствует, „дефектному“ кислороду $\mathrm{O}_{\mathrm{def}}$ (атом кислорода, примыкающий к вакансиям Ni), которая появляется вследствие высоко дефектной структуры $\mathrm{NiO}$ [11]. Кроме того, при разложении спектров О $1 s$ можно выделить более слабые линии с энергиями связи 533.3 и $532.1 \mathrm{eV}$, которые относятся к адсорбированной воде и кислородосодержащим органическим соединениям на поверхности. В спектрах углерода основная широкая полоса с энергией связи состоит из вкладов графитоподобного углерода с $s p^{2}$-гибридизацией
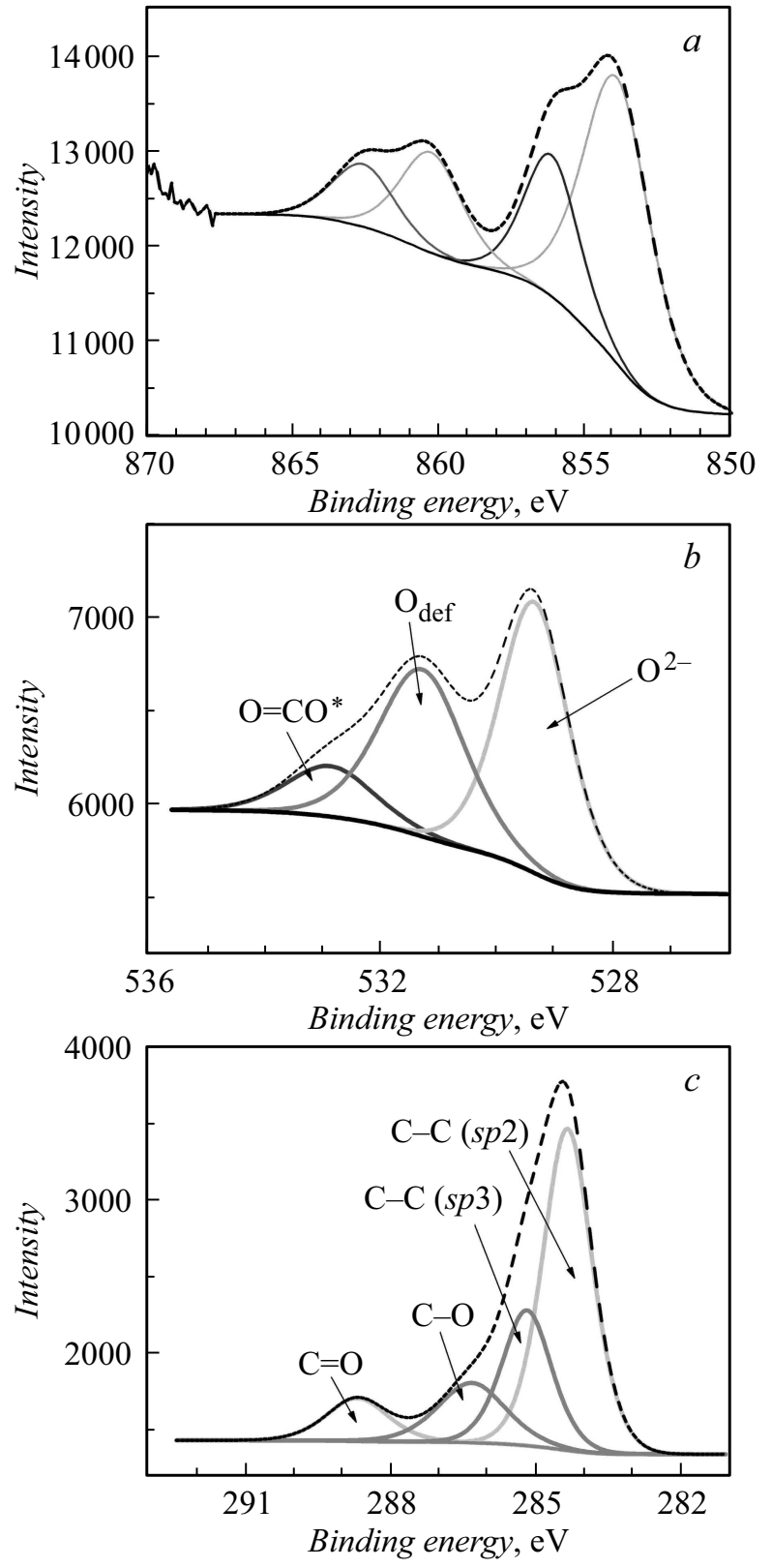

Рис. 4. РФЭС образца УК2 после нагрева до температуры $550^{\circ} \mathrm{C}$ в потоке аргона с кислородом. $a-$ линия $\mathrm{Ni} 2 p$, диапазон 850-870 eV; $b$ - линия O $1 s$, диапазон $527-536 \mathrm{eV}$; $c$ - линия C $1 s$, диапазон $281-293 \mathrm{eV}$.

$(284.5 \mathrm{eV})$ и углерода с $s p^{3}$-гибридизацией $285.3 \mathrm{eV}$ (рис. 4,b). Кроме того, можно выделить линии 286.3 и $288.6 \mathrm{eV}$, которые могут быть отнесены к спиртовым и карбоксильным группам соответственно. Ионное травление приводит к некоторому увеличению доли $s p^{3}$-гибридизации за счет разупорядочения графитоподобных слоев.

По методу ПЭМ было установлено, что УК2 после нагрева в потоке аргоно-кислородной смеси при описанных выше условиях содержит частицы, покрытые углеродной оболочкой (рис. 5). 


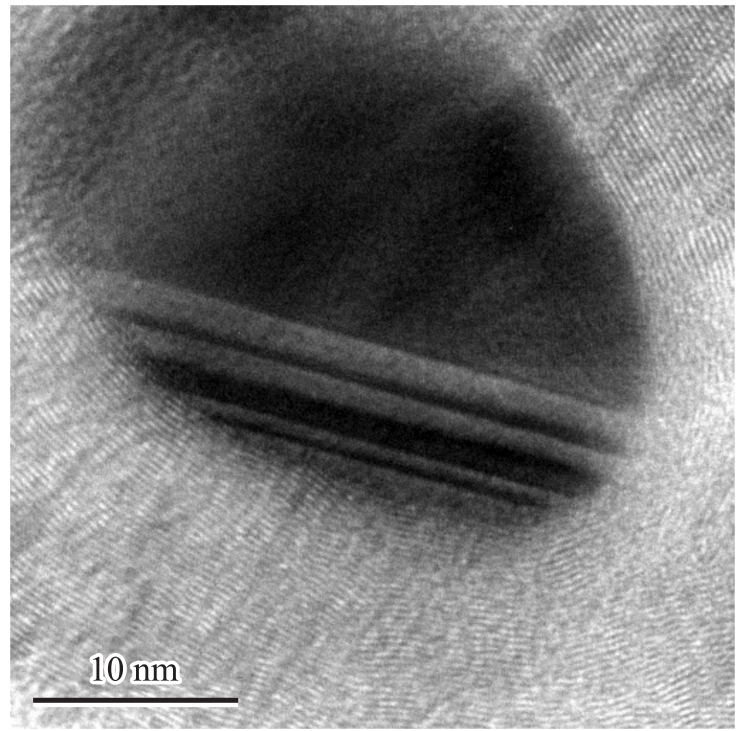

Рис. 5. Изображение образца УК2 после нагрева, полученное с помощью метода ПЭМ на приборе JEOL JEM-2100, ускоряющее напряжение $200 \mathrm{kV}$.

Основываясь на данных, полученных с помощью РФЭС и электронной микроскопии, можно сделать вывод, что УК, полученный в ВЧ плазме, содержит частицы на основе никеля, имеющие структуру ядро-оболочка. В качестве ядра выступает поликристаллический никель, а оболочка представляет собой углерод с $s p^{3}$-гибридизацией вблизи никелевого ядра, переходящей в углерод с $s p^{2}$-гибритизацией на внешней границе оболочки частиц. В процессе нагрева в присутствии кислорода никелевое ядро окисляется при этом углеродная оболочка остается до температуры $600^{\circ} \mathrm{C}$. При дальнейшем повышении температуры углеродная оболочка сгорает, оставляя ядро из поликристаллических наноразмерных частиц оксида никеля.

\section{Заключение}

В настоящей работе показано, что все фазы, содержащиеся в УК1 образующемся при дуговом способе распыления графитовых стержней, т.е. при синтезе фуллеренов, в потоке кислород-аргоновой смеси газов выгорают, но с разными температурами максимумов горения. Процессы горения различных фаз накладываются, что позволяет сделать вывод о невозможности выделения какой-либо фазы углерода методом термического окисления в потоке кислорода. Введение никеля в процессе распыления приводит к возникновению частиц со структурой углеродная оболочка-никелевое ядро. УК2, содержащий такие частицы, взаимодействует с кислородом более интенсивно и процесс максимальной интенсивности горения всех фаз смещается в более низкие температуры. При нагреве до температуры $550^{\circ} \mathrm{C}$ в присутствии кислорода образца УК2 ядра частиц из никеля окисляются, при этом оболочка из углерода остается стойкой. Углеродная оболочка никелевых частиц выгорает в потоке кислород-аргоновой смеси лишь в диапазоне температур $660-920^{\circ} \mathrm{C}$. А именно существует температурная зона, прекратив подачу кислорода в которой, можно остановить выгорание углеродной оболочки частиц. Таким образом, термическое окисление позволяет выделять частицы ядро (оксид никеля)-углеродная оболочка из УК, полученного при введении никеля в процесс синтеза.

\section{Благодарности}

Исследование при помощи метода ПЭМ выполнено с использованием оборудования Омского регионального ЦКП СО РАН.

Исследование выполнено при финансовой поддержке Российского фонда фундаментальных исследований, правительства Красноярского края, Красноярского краевого фонда поддержки научной и научно-технической деятельности в рамках научного проекта № 16-43-242148.

\section{Список литературы}

[1] Белов П.С., Голубева И.А., Низова С.А. Экология производства химических продуктов из углеводородов нефти и газа. М.: Химия, 1991. 256 с.

[2] Крылов О.В. Технология катализаторов / Под ред. И.П. Мухленоваю 3 изд. Л.: Химия, 1989. 328 с.

[3] Петраковская Э.А., Булина Н.В., Чурилов Г.Н., Пузырь А.П. // ЖТФ. 2001. Т. 7. Вып. 1, С. 44.

[4] Bulina N.V., Lopatin V.A., Vnukova N.G., Osipova I.V., Churilov G.N. // Fullerene, Nanotubes, and Carbon Nanostructures. 2007. Vol. 15. N 5. P. 395-400.

[5] Лякишев Н.П. Диаграммы состояния двойных металлических систем: Справочник. М.: Машиностроение, 1996. $330 \mathrm{c}$.

[6] Чурилов Г.Н., Кореи, А.Я., Титаренко Я.Н. // ЖТФ. 1996. Т. 66. Вып. 1. С. 191-194.

[7] Чурилов Г.Н., Баюков О.А., Петраковская Э.А., Кореи, А.Я., Исакова В.Г., Титаренко Я.Н. // ЖТФ. 1997. Т. 67. Вып. 9. С. $142-144$.

[8] Chen H.S., Kortan A.R., Haddon R.C., Fleming D.A. // J. Phys. Chem. 1992. N 96. P. 1016-1018.

[9] Yu-Chen Hsieh, Yu-Chuan Chou, Chun-Ping Lin, TungFeng Hsieh, Chi-Min Shu // Aerosol Air Quality Research. 2010. N 10. P. 212-218.

[10] Biesinger M.C., Payne B.P., Lau L.W.M., Gerson A., Smart R.St.C. // Surf. Interf. Analys. 2009. N 41. P. 324-332.

[11] Biesinger M.C., Payne B.P., Grosvenor A.P., Lau L.W., Gerson L.A.R., Smart R.St.C. // Appl. Surf. Sci. 2011. N 257. P. 2717-2730.

[12] Payne B.P., Biesinger M.C., McIntyre N.S. // J. Electron Spectr. Related Phenomena. 2012. N. 185. P. 159-166. 